\title{
A single-subject evaluation of the treatment of morphing fear
}

\section{Article}

\section{Accepted Version}

Creative Commons: Attribution-Noncommercial-No Derivative Works 4.0

Zysk, E., Shafran, R. and Williams, T. I. (2018) A singlesubject evaluation of the treatment of morphing fear. Cognitive and Behavioral Practice, 25 (1). pp. 168-181. ISSN 1077-7229 doi: https://doi.org/10.1016/j.cbpra.2017.03.003 Available at https://centaur.reading.ac.uk/68954/

It is advisable to refer to the publisher's version if you intend to cite from the work. See Guidance on citing.

To link to this article DOI: http://dx.doi.org/10.1016/j.cbpra.2017.03.003

Publisher: Elsevier

All outputs in CentAUR are protected by Intellectual Property Rights law, including copyright law. Copyright and IPR is retained by the creators or other copyright holders. Terms and conditions for use of this material are defined in the End User Agreement.

\section{www.reading.ac.uk/centaur}

\section{CentAUR}

Central Archive at the University of Reading

Reading's research outputs online 


\section{A Single-Subject Evaluation of the Treatment of Morphing Fear}

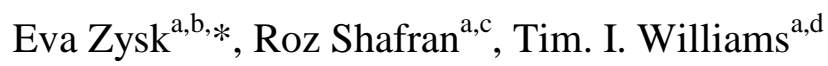

${ }^{\mathrm{a}}$ School of Psychology and Clinical Language Sciences, University of Reading, Whiteknights, Earley Gate, Reading, Berkshire, UK, RG6 6AL

*Corresponding author: Eva Zysk, eva.zysk@ntu.ac.uk, Tel: +44 115848 5599, Nottingham Trent University, Division of Psychology, Burton Street, Nottingham, UK, NG1 4BU

${ }^{\mathrm{b}}$ Present address: Nottingham Trent University, Division of Psychology, Nottingham, UK

${ }^{\mathrm{c}}$ University College London, Institute of Child Health, London, UK

${ }^{\mathrm{d}}$ University of Reading, Institute of Education, Reading, UK

Key words: morphing fear, transformation obsession, mental contamination, obsessive-compulsive disorder, treatment efficacy

Acknowledgements: This research was supported by the Charlie Waller Memorial Trust. 


\section{Highlights:}

- Morphing fear is considered to be a variant of contamination-based OCD

- Poor recognition, assessment and understanding has contributed to treatment failures

- Standard CBT for OCD needs adaptation to target the cognitive nature of morphing fear

- We demonstrate the efficacy of an adapted CBT treatment protocol in a single subject 


\title{
A Single-Subject Evaluation of the Treatment of Morphing Fear
}

\begin{abstract}
We present a single-subject prospective outcome study of a man with severe morphing fear who was not helped by previous interventions, and who received an adapted form of cognitive behaviour therapy (CBT) as part of this study. Treatment consisted of a cognitively-focused approach tailored to address his fear of morphing and included helping him develop a stronger sense of self-stability. We describe the details of the case, the treatment protocol, and the therapeutic outcomes as assessed by questionnaires, rating scales and semi-structured interviews over 36 weeks. The intervention was effective in eradicating the patient's morphing fears and reducing other symptoms of OCD, anxiety and depression. The presented case illustrates the need to appropriately conceptualize, assess and address the specific nature of morphing fear symptoms in treatment.
\end{abstract}

Key words: morphing fear, transformation obsession, mental contamination, obsessivecompulsive disorder, treatment efficacy 


\section{Introduction}

The current National Institute for Health and Care Excellence (NICE) guidelines (2005) recommend cognitive behavioural therapy (CBT) incorporating exposure and response prevention (ERP) for the treatment of Obsessive Compulsive Disorder (OCD) in the UK. Unfortunately, there remains considerable scope for improvement in treatment efficacy with various studies showing that following the recommended treatment for OCD only up to one-quarter of patients demonstrate complete recovery (Abramowitz, Franklin, \& Foa, 2002; Boschen, Drummond, \& Pillay, 2008; Eddy, Dutra, Bradley, \& Westen, 2004; Fisher \& Wells, 2005). Some evidence suggests that treatment outcomes for contamination-related OCD in particular are modest; many contaminationfearful patients do not achieve symptom relief or commonly relapse following initial successful treatment (Coelho \& Whittal, 2001, cited in Rachman, 2004; McLean et al., 2001). Given that contamination fears account for up to 55\% of people with OCD (Calamari et al., 2004; Foa \& Kozak, 1995; Rachman, 2004; Rachman \& Hodgson, 1980; Rasmussen \& Eisen, 1992), increasing success rates of contamination fear treatment is imperative.

One potential explanation for the poor outcomes of contamination fears is the failure to conceptualize these symptoms adequately. This may in part be due to over-attention paid to contact contamination and overlooking contamination fears which arise in the absence of physical contact (i.e. mental contamination; Fairbrother \& Rachman, 2004; Rachman, 2006; Radomsky \& Elliott, 2009) and those which may present as more obscure symptoms (i.e. morphing fears, cf. Rachman, 2006; Volz \& Heyman, 2007). It has previously been suggested that different OCD symptom profiles may require tailored CBT interventions to increase efficacy of treatment (Freeston et al., 1997; Keeley, Storch, Merlo, \& Geffken, 2008; Sookman et al., 2005; Williams, Salkovskis, Forrester, \& Allsopp, 2002). NICE guideline-recommended treatment for OCD may need adaptation for mental contamination and morphing fears in order to specifically target the key presenting symptoms of these OCD manifestations. 
Mental contamination is defined by feelings of dirtiness and urges to wash which arise in the absence of direct contact with a noxious substance or following contact with something others would not deem contaminating (Rachman, 1994, 2004, 2006). Morphing fear, a type of mental contamination (Coughtrey et al., 2013; Rachman, 2006; Zysk, Shafran, Williams \& Melli, 2015), involves worries that one may become tainted by and acquire unwanted characteristics of others through contagion. Patients commonly interpret this fear as becoming contaminated and harmed by others' qualities (Coughtrey et al., 2012; Monzani et al., 2015; Rachman, 2006) thereby bearing resemblance to other contamination fears, although overt washing/cleaning compulsions may or may not present. Morphing fears commonly present as avoidance of a specific person or group who may be deemed inferior or undesirable, with compulsions presenting in overt (e.g. washing, checking, reassurance seeking) and covert (e.g. mental cleansing, neutralising) forms. Unlike with contact contamination, the source of mental contamination and morphing fears is cognitive; for instance, morphing fears can be elicited through looking at, hearing or thinking about an undesirable person. Additionally, the resulting feelings of contamination are internal and psychological. As such, the site of contamination is not physically accessible, and washing is misdirected and often does not bring relief (Rachman, 2006).

The prominent symptom in morphing fear is an underlying concern about magical transformation, a cognitively-based fear grounded in a cause-and-effect distortion that patients recognize as irrational. The intrusive recurring nature of the thoughts has led morphing fears to also be referred to as "transformation obsessions" (Monzani et al., 2015; Volz \& Heyman, 2007) and these symptoms have recently been found to load onto the forbidden thoughts dimension of the Children's Yale-Brown Obsessive-Compulsive Scale checklist (Scahill et al., 1997) in children (Monzani et al., 2015). The cognitive nature of morphing fears is also reflected in patients' unstable sense of self and concurrent low self-esteem (cf. Rachman, 2006). People with OCD hold uncertain self-perceptions and are prone to experiencing ego-dystonic intrusions as personally threatening to 
their sense of self (Bhar \& Kyrios, 2007; Ferrier \& Brewin, 2005; Guidano \& Liotti, 1983; Lipton, Brewin, Linke, \& Halperin, 2010). Such intrusions may lead some people to fear they may become someone undesirable (O'Connor et al., 2005; Wu, Aardema \& O’Connor, 2009) which may help explain morphing fears. Previous research has also shown links between feared self-beliefs and selfdoubt in OCD (Nikodijevic, Moulding, Anglim, Aardema, \& Nedeljkovic, 2015). In addition, selfesteem — which is thought to be linked with self-uncertainty (Campbell, 1990)—may be affected by the exaggerated importance of intrusions about patients' identity (Ferrier \& Brewin, 2005) and morality (Shafran, Thordarson, \& Rachman, 1996). As such, these cognitions may lead patients to engage in compulsions such as checking and neutralising to reduce the doubt and threat and to correct any perceived deviation from the actual self (cf. Bhar \& Kyrios, 2007; Guidano \& Liotti, 1983).

Three treatment recommendations for morphing fears have been proposed: exposure and response prevention (ERP; Hevia, 2009), standard CBT treatment (Monzani et al., 2015; Volz \& Heyman, 2007), and theory-driven cognitively-focused CBT (Rachman, 2006; Rachman, Coughtrey, Shafran, \& Radomsky, 2015). Hevia (2009) describes a retrospective case of a male who was successfully treated with a course of ERP. Volz and Heyman (2007) and Monzani et al. (2015) suggest the same application of CBT for morphing fear as for other symptoms of OCD; this approach was used for children with OCD who were additionally retrospectively found to have had morphing fears, and showed comparable success in their general OCD reduction as those with OCD not having reported any morphing fears (Monzani et al., 2015). However, given the cognitive nature of morphing fears, Rachman (2006; Rachman et al., 2015) argues that morphing fears require a cognitively-focused CBT approach similar to that for mental contamination. A cognitive focus allows for idiographic treatment to address specific OCD symptom presentation and target underlying cognitive processes that contribute to their maintenance (cf. Rachman, 2003; Whittal, Robichaud, \& Woody, 2010; Wilhelm et al., 2009). Specifically, Rachman proposes techniques 
aimed to target maladaptive cognitions and key underlying beliefs and working with the patient to develop a stronger sense of self-stability could prove useful in alleviating morphing fears. This treatment has since been shown to be effective (cf. Coughtrey et al., 2013; Rachman et al., 2015).

From the morphing fear research to date, Coughtrey et al.'s (2013) study is the only one to have utilized a prospective design; the retrospective nature of the research by Hevia (2009), Volz and Heyman (2007) and Monzani et al. (2015) does not permit for confidence in their findings. A further critical limitation of published work to date rests in that reduction of morphing fears was not systematically measured so it is unclear to what extent treatment gains were morphing-fear specific.

The aim of the current study is to evaluate a theory-driven cognitive behavioral intervention specifically focused on morphing fears based on Rachman's (2006; Rachman et al., 2015) treatment recommendations, and with a heavy focus on working to build a robust sense of self. It is hypothesized that this specialized treatment would result in clinically significant decreases in morphing fears, mental contamination, obsessive-compulsive (OC) symptoms, anxiety, and depression. This study uses a single-subject multiple baseline design to test the hypotheses. Singlesubject designs are critical in testing theoretically-derived interventions and establishing evidencebased practice (Agras \& Berkowitz, 1980; Horner et al., 2005; Kazdin, 1982; Salkovskis, 2002), and are particularly important where there have been previous treatment failures, when no specific treatments exist, and in investigations involving unusual or rare phenomena (Blampied, 1999; Kazdin, 1982). Single-subject designs are rigorous methods for evaluating treatment efficacy (Horner et al., 2005) and are thought to provide the greatest understanding of treatment effects (Barlow, 1981; Shadish, Cook, \& Campbell, 2002; Valsiner, 1986). The existence of a new valid and reliable measure to assess morphing fears (Morphing Fear Questionnaire; Zysk et al., 2015) allows the current research to improve on past treatment studies in order to provide unequivocal support for symptom change. The use of this measure also allows for an objective, clear and 
complete definition of morphing fears, thereby meeting the criteria put forth by Hawkins and Dobes (1977).

\section{Methods}

Design

An A-B design was used in which symptoms of one patient were assessed over 36 weeks: symptoms were monitored at baseline before the intervention was applied and throughout treatment until after its completion. This study received NHS (XX/XX/XX) and university ethical approval.

\section{Participant}

James $^{1}$ was a male in his twenties who was referred by a mental health practitioner. The referral mentioned James's OCD symptoms (e.g. compulsive washing and checking), symptoms of mental contamination (e.g. feelings of dirtiness following conflict), and symptoms which suggested possible morphing fears (e.g. worries that he will be weakened as a person). Upon assessment, the patient was confirmed to have a primary diagnosis of OCD; have morphing fears which cause significant distress and interference; not be actively psychotic or suicidal, and not be receiving any concurrent psychological treatment; and was thereby suitable for treatment. James had a 15 year history of OCD. Prior treatment included face-to-face and phone sessions of counselling which James described as very unhelpful. He had been previously prescribed Fluoxetine for depression and anxiety on two occasions. At the time of the assessment and treatment James was not taking any psychotropic medications.

James presented with severe morphing concerns related to a fear of losing his intelligence and becoming an immoral person. He feared he could become "infected with unseeable germs" and change to be like another person through physical contact or proximity, or through a negative

\footnotetext{
${ }^{1}$ Personal details have been changed to protect the patient's identity. Details of the case (referred to as "Joanne") have been presented elsewhere (AUTHORS REMOVED, in press).
} 
atmosphere created by a person or group. The feared changes could involve physical (e.g. becoming less attractive or disabled), moral (becoming violent, sexist, racist, or "sleazy"), emotional (acquiring a negative mood or becoming insecure or pathetic), or intellectual transformations (adopting superstitions, shallow opinions, or viewpoints he did not endorse). Additionally, James felt that he needed to maximize his potential and every intellectual and social opportunity due to intrusions that if he did not understand something he could become diminished as a person. When James felt diminished or experienced low mood, stress or embarrassment, he felt he could physically change. In particular, he worried he could become shorter in stature - that he could literally become a smaller person. James was also concerned about the possibility of reverse morphing. He feared he could infect others with his depression and beliefs, and that others could take away his positive traits for their own use.

The patient was preoccupied by these distressing fears a large proportion of the time and engaged in avoidance and compulsions which were primarily geared at stopping him from "losing himself". Compulsions involved hand-washing, performing actions in 3s, touching "safe" objects, repetition of information, and checking compulsions comprising thinking of three personal facts within a set time limit to verify he was still himself. Due to fears of being wrong or taken off-guard in a conversation and thereby appearing stupid, James avoided making an argument unless he was confident he was correct, and he reported feelings of panic in some social situations. James avoided engaging in banal conversation and exposing himself to shallow opinions or situations which fail to stimulate him as he believed these could contaminate him by eroding his intelligence or potential and making him dull and uninteresting. James's need to excel in his work was in part driven by this fear; he felt his only salvation was to be able to pursue higher career goals and to be in the company of other critically-thinking intellectuals. Ironically, one significant impact of James's morphing fears related to him not doing well in his work. This caused him great distress and anxiety, and contributed to his feelings of depression and hopelessness. Feelings of depression, in turn, provided 
support for James's belief that he could acquire negative mood and self-pity through morphing, and thereby contributed to fear maintenance. In a similar manner, James's disorganisation and lack of routine and sleep caused him to look and feel tired which he sometimes took as evidence of change. James additionally had perfectionistic standards which helped maintain the disorder.

An individualized formulation based on a cognitive-behavioral model of OCD (Whittal, Woody, McLean, Rachman, \& Robichaud, 2010) and theory of mental contamination (Rachman, 2006) was drawn up between James and his therapist in the first session (see Figure 1).

\section{[INSERT FIGURE 1 ABOUT HERE]}

\section{Materials}

Morphing Fear Questionnaire (MFQ; Zysk, Shafran, Williams \& Melli, submitted). This brief 13-item self-report measure assesses for the presence and severity of morphing fears on a 5-point Likert scale from 0 (not at all) to 4 (very much). Respondents are asked to provide a short explanation or specific example for any two questions with which they agree much/very much. This unidimentional measure has shown excellent internal consistency in an OCD sample $(\alpha=.90)$, good temporal stability $(r=.73)$, and excellent construct validity (e.g. convergence with the OCI-R and VOCI-MC, and divergence with BDI-II and BAI). The MFQ has shown evidence of criterionrelated validity in its ability to discriminate between groups reporting OCD, anxiety, depression and no OCD.

Vancouver Obsessional Compulsive Inventory - Mental Contamination Scale (VOCI-MC; Rachman, 2006). This 20 -item self-report measure assesses presence of mental contamination using items such as "I often feel dirty inside my body" rated on a 5-point Likert scale (0-4). The VOCIMC has excellent internal consistency (Cronbach's $\alpha=.93-.97)$, good convergent validity with the contamination subscale of the VOCI (cf. Thordarson et al., 2004) and divergent validity with symptoms of depression on the BDI-II, and good discriminant validity between those with 
contamination OCD and other groups (Radomsky, Rachman, Shafran, Coughtrey \& Barber, 2014). An OCD contamination-fearful sample had a mean score of 30.6, while a non-clinical sample had a mean of 8.3 (Radomsky et al., 2014).

Obsessional Compulsive Inventory - Short Version (OCI-R; Foa et al., 2002). The OCI-R assesses for OCD symptoms on 6 subscales using 18 items rated on a 5-point Likert scale from 0 (not at all distressed/bothered) to 4 (extremely distressed/bothered). This self-report measure is reported to have good to excellent internal consistency, temporal stability, and convergent validity (e.g. washing subscale: Cronbach's $\alpha=.86 ; r_{\mathrm{s}}=.86$; strong correlation with Rachman and Hodgson's 1980 Maudsley Obsessive-Compulsive Inventory washing subscale, $r_{\mathrm{s}}=.78$, respectively). The mean for OC and non-clinical samples have been reported to be 28.0 and 18.8 respectively.

Beck Anxiety Inventory (BAI; Beck \& Steer, 1990). The BAI lists 21 symptoms of anxiety on which participants rate their symptom severity using a 4-point scale (from 0: not at all to 3: severely). The BAI is widely used in research and clinical practise, and has excellent internal consistency (Cronbach's $\alpha=.94$ ) and acceptable test-retest reliability ( $r=.67$; Fydrich, Dowdall, \& Chambless, 1992). The non-clinical mean for this measure has been reported between to be 6.6 (Gillis, Haaga, \& Ford, 1995) and 13.4 (Creamer, Foran, \& Bell, 1995) while the clinical mean has been found to be 25 in those with a primary anxiety disorder (Beck, Epstein, Brown, \& Steer, 1988).

Beck Depression Inventory-II (BDI-II; Beck, Steer \& Brown, 1996). The 21-item self-report measure assesses the presence and severity of the affective, cognitive, motivational, psychomotor, and vegetative components of depression. Items are scored from 0 (absent) to 3 (severe). The BDIII has shown excellent internal consistency (Cronbach's $\alpha=.91)$ and test-retest reliability $(r=.93)$, and is one of the most widely used measures for assessing depression in research and clinical contexts. The non-clinical mean has been reported to be between 8.4 (Whisman, Perez \& Ramel, 
2000) and 12.6 (Beck et al., 1996), while the clinical mean for those with depression has been reported at 21.9 (Beck et al., 1996),

Anxiety Disorders Interview Schedule (ADIS-IV, Brown, Di Nardo \& Barlow, 1994). This is a widely used semi-structured diagnostic interview with excellent psychometric properties. It assesses current episodes of mental health disorders such as anxiety and depression in accord with DSM-IV criteria (APA, 1994).

Yale-Brown Obsessive Compulsive Scale (Y-BOCS; Goodman et al., 1989a). This semistructured interview employs both a checklist to assess the nature of the disorder and a 10-item 0-4 Likert scale to measure the severity of obsessions and compulsions. It has established excellent reliability and validity (Goodman et al., 1989a, 1989b). The Y-BOCS is sensitive to treatment effects and is considered the "gold-standard" assessment measure in treatment outcome research (Frost, Steketee, Krause, \& Trepanier, 1995; Taylor, 1995). There has been no established nonclinical normative data for the Y-BOCS (Fisher \& Wells, 2005); however, it is generally accepted that a total score of $\leq 12$ is indicative of a functional, non-clinical state (cf. Fisher \& Wells, 2005; e.g. McLean et al., 2001). A total score of $\geq 16$ signifies clinically symptomatic levels and is typically used as entry criteria for treatment trials (Tolin, Abramowitz, \& Diefenbach, 2005).

Standardized Interview Schedule-Contamination (Shortened Version) (Rachman, 2006). This interview assesses for the presence and features of contact and mental contamination, with two questions specifically assessing for the presence of morphing fears.

Visual Analogue Scale (VAS): A series of $10 \mathrm{~cm}$ VASs were used to measure self-report current ratings of internal dirtiness, general dirtiness, washing/neutralising urges, and anxiety. Each scale was anchored with the labels Not at all to Extremely. The VASs were used as session-by-session measures given that such measurement has been shown to improve outcome (cf. Lambert, 2009; Lambert, et al., 2001). Additionally, VASs are reliable and valid (Reips \& Funke, 2008), help rule 
out threats to internal validity related to assessment (cf. Kazdin, 1982), and are recognized to be sensitive to clinical change (cf. McCormack, Horne, \& Sheather, 1988).

\section{Procedure:}

James was seen within 15 days of his referral for an assessment with a clinical psychologist ([INITIALS REMOVED], the second author) as part of a research study. He completed a battery of questionnaires (i.e. the MFQ, VOCI-MC, OCI-R, BAI \& BDI-II) the day before the initial assessment which he was asked to bring to the appointment. James provided written informed consent to taking part in the research, being audiotaped in treatment and assessment sessions, and for his case to be presented in in any publications.

Clinical Assessment: An initial 90 minute clinical assessment was conducted with the therapist following the adaptations put forth by Rachman (2006; Rachman et al., 2015) to get a thorough understanding of the main presenting problem, its history and onset. This included: using tools specific to assessment of mental contamination (e.g. VOCI-MC) and morphing fears (MFQ); determining the source(s) of feelings of contamination and morphing triggers; determining the feared/believed mechanism of morphing and assessing the personal vulnerability to contamination and morphing; and understanding specific maintaining mechanisms of the fear and how the patient makes sense of the problem and its maintenance.

Independent research assessments: Regular research assessments were held 8-11 weeks apart by an experienced independent assessor ([INITIALS REMOVED], the first author) who was blind to when the treatment commenced. The initial research assessment (Week 0) was conducted one week after the clinical assessment and comprised the ADIS-IV, Y-BOCS, Standardized Interview Schedule for Contamination, a brief interview based on high scores on the initial MFQ, and the VAS. All subsequent research assessments comprised only the ADIS-IV, Y-BOCS and VAS. The patient was asked to complete the battery of questionnaires online within one day of each of the 4 
subsequent research assessments to collect self-reported symptoms. A delay was planned before the start of treatment to assess for symptom improvement without intervention. The second baseline research assessment was completed at Week 9, just prior to the commencement of treatment which (unbeknown to the assessor) was scheduled to begin the same day. The final assessment was held 2.5 weeks after the end the final session.

Session-by-session assessments: The patient also completed the VAS at the start of each treatment session to collect regular and frequent assessment over time in order to monitor treatment progress (cf. Egan \& Hine, 2008; Kazdin, 1982).

Treatment: Fifteen hour-long sessions were delivered over the course of 22 weeks, with two sessions being delivered in the first week (cf. Agras, Walsh, Fairburn, Wilson, \& Kraemer, 2000; Riley, Lee, Cooper, Fairburn, \& Shafran, 2007). The main morphing-fear targeted approach occurred in the first 12 sessions, with the final 3 sessions focusing primarily around residual symptoms of low mood. The therapist delivering the treatment is experienced in treating mental contamination and morphing fears. The detailed background for the choice of this approach is provided in [AUTHORS REMOVED] (submitted). The treatment was based on modified Cognitive Behavior Therapy for mental contamination (Coughtrey et al., 2013) and focused on addressing morphing fears and other presenting problems (mental contamination, depression and perfectionism). The following elements were added to target James's morphing fears (cf. Rachman, 2006; Rachman et al., 2015):

- Psychoeducation about mental contamination, morphing fears, stability of characteristics and possibility of transference of qualities

- Addressing cognitive biases, testing beliefs and challenging assumptions that maintained symptoms, such as through behavioral experiments assessing the feasibility of change (e.g. 
using photographs and height measurements to test James's belief that mood can alter physical features)

- Cognitive restructuring through evaluating negative automatic thoughts and beliefs (e.g. "I am losing my potential") such as in keeping thought records; and operationalising "maximum potential"

- Differentiating between feelings and facts and accurately labelling mood states (e.g. distinguishing between feelings of contamination and negative emotions, for instance labelling a particular emotional state as "stressed" rather than "diminished")

- Cognitive-behavioral approaches to strengthen and broaden sense of self-identity and address self-esteem issues (e.g. listing his stable characteristics, devising a pie chart of the multifaceted nature of his personality [based on Fairburn, 1995]).

Non-specific interventions included: psychoeducation on healthy lifestyle and regular eating, sleeping patterns and routines; organisational aids to manage professional workload; surveys to assess what others deem important in maximising their success (e.g. balanced lifestyle versus thoroughness); work on perfectionism such as use of continuum techniques (Beck, 1995) and helping James exercise moderation in his work and decrease avoidance and procrastination (Shafran, Egan, \& Wade, 2010); relaxing strict rules; tackling self-criticism and low mood; use of problem solving and stress-reduction techniques; and encouraging confiding in others.

Homework in the form of thought records, surveys and behavioral experiments aimed to address morphing fears was assigned between sessions. The treatment terminated with the therapist and patient devising a relapse prevention plan reviewing what was done in treatment, what the patient found to be useful, and how to spot the early signs of a relapse. To summarize treatment gains in his morphing symptoms, James was asked to think about how his identity has solidified and 
become more robust, and how this has contributed to a decrease in his perceived vulnerability to morphing, and consequently a reduction of his morphing fears.

\section{Results}

Table 1 presents the outcome of each of the 5 research assessments. James did not complete the online measures at Week 20 so data is missing for this time point on the VOCI-MC, OCI-R, BAI, and BDI-II (he completed the MFQ by email).

[INSERT TABLE 1 ABOUT HERE]

\section{Experimental Criterion}

The magnitude and rate of the change of symptoms across different phases were visually inspected in accordance with recommendations for addressing the experimental criterion in singlesubject research (cf. Kazdin, 1982; Parsonson \& Baer, 1986). Changes in the mean and trend were most relevant to the research assessment data, whereas changes in mean, trend and latency of the change were most relevant to the session-by-session assessments, and these were accordingly examined. Figures 2-4 present James's symptoms over time on the MFQ, Y-BOCS, VOCI-MC, OCI-R, BAI, and BDI-II as assessed at each research assessment.

\section{[INSERT FIGURES 2, 3 AND 4 ABOUT HERE]}

The severity of morphing fears, mental contamination, OC symptoms assessed by the Y-BOCS, and depression was stable over the two baseline assessments in contrast to the decline seen during treatment. On all measures there was an evident downward trend between phases and a change in mean that were especially pronounced on the MFQ and OCI-R. Symptom stability or a further decrease on the measures could be seen at follow-up. The only exception was mental contamination which showed an increase between weeks 28 and 36. 
Figure 5 displays the VAS measures as collected at baseline (bl-1 \& bl2-S1), at the start of each treatment session (sessions "S" 2-15), and at a 2.5 week follow-up (FU).

\section{[INSERT FIGURE 5 ABOUT HERE]}

A change in mean is evident between the baseline and treatment phases, and this is maintained at follow-up. All reported symptoms indicate a clear downward trend over the course of treatment. The graph also shows a sharp decline between Sessions 5 and 7, and a decrease in variability by the final few sessions and follow-up.

To supplement the visual analysis (cf. Manolov, Losada, Chacón-Moscoso \& SanduveteChaves, 2016) and measure data non-overlap between two phases accounting for level and trend, the Tau- $U$ statistic was used (cf. Parker, Vannest, Davis \& Sauber, 2011; Vannest, Parker \& Gonen, 2011) This analysis was carried out for the combined 5 research assessment measures relevant to OCD symptomatology (MFQ, VOCI-MC, Y-BOCS, OCI-R and BAI), and for the combined VAS (internal and general dirtiness, urge to wash, and anxiety). The omnibus Tau- $U$ effect size as assessed by the 5 measures was -0.96 signifying a large intervention effect (Parker \& Vannest, 2009), and this non-overlap in confidence intervals between the baseline and treatment phase was found to be significant, $z=-3.48, p<.001,90 \%$ CI $[-1.420,-0.509]$. The Tau- $U$ effect size as assessed by the VASs was -0.49 signifying a small intervention effect. The difference between the two phases was also significant, $z=-2.20, p=.028,90 \%$ CI $[-0.860,-0.124]$. The weighted averages of the research assessments and the VAS measurements both met the recommended minimum effect size for practical significance (RMPE) for social sciences (i.e. 0.2; Ferguson, 2009).

\section{Therapeutic Criterion}

The data were additionally analysed to assess the impact (i.e. clinical significance) of the treatment by determining if the patient's scores after treatment are closer to the mean of the 
functional than the dysfunctional population (cf. Jacobson \& Truax, 1991; definition c). Table 2 reports clinical significance was achieved on all but one measure.

\section{[INSERT TABLE 2 ABOUT HERE]}

\section{Discussion}

The results provide preliminary evidence for the efficacy of a cognitively-focused intervention for morphing fear which concentrates on solidifying the patient's sense of self. Prior to treatment, James's fear caused him anxiety and was disruptive to his professional and social life. In the final post-treatment assessment James reported no morphing fear; he was no longer concerned about acquiring negative characteristics of others, being diminished and losing his intelligence, and his score on the MFQ was indistinguishable from a population without morphing fears. James developed a more robust sense of self and shed his belief that his response to negative events could cause physical changes in himself.

The treatment protocol was based around the theory that morphing fear is maintained by a low sense of self-stability and low self-esteem (cf. Rachman, 2006; Rachman et al., 2015). James's formulation revealed fragile self-concept, poor self-esteem, and doubts about his personal characteristics were maintaining factors of his symptoms. Additional maintaining factors in James's case included perfectionism (e.g., in his strive to be intelligent and his fear that his intelligence could be eroded through morphing), depression (e.g., he considered low mood as evidence of morphing), and disorganisation (e.g., lack of regular routine causing physical signs of tiredness which were mistaken as evidence for becoming diminished). Uncertainty about the self and low self-esteem have been found to be closely associated with OCD symptoms (cf. Campbell, 1990), and low levels of self-esteem, high anxiety and high depression have been linked with feelings of instability about one's character (e.g. Campbell \& Lavallee, 1993; Donahue, Robins, Roberts, \& John, 1993). Ambivalent feelings about the self have also been used to explain why those with OCD 
have perfectionism, in that they strive towards high standards of personal characteristics and conduct (Bhar \& Kyrios, 2007). Perfectionism and compulsions have been noted as defensive strategies aimed to protect one's desirable self-image in people with OCD (Guidano \& Liotti, 1983). Each of these maintenance factors was addressed in therapy. Providing alternative appraisals of the threat (e.g. that intelligence is important to him and he worries about the threat of its loss) appeared to play a significant role in James's treatment and provided confidence that cognitivelyheavy CBT incorporating work on the sense of self was appropriate and effective for morphing fear reduction.

The treatment also resulted in clinically significant decreases in the patient's OC symptoms, anxiety and depression levels. After treatment James no longer met diagnostic criteria for social phobia, and other symptoms of anxiety had decreased. This is noteworthy in light of the fact that although some anxiety-reducing techniques were introduced (e.g. relaxation), anxiety was not a focus of treatment. Depression symptoms, which were targeted, also decreased between baseline and post-treatment. In the final post-treatment assessment James continued to report mild OCD; however, residual OCD symptoms were limited to adhering to certain rules and sequences and some internal counting compulsions which James explained to be doing out of habit and which only caused him mild distress and interference. James's obsessional routines had decreased significantly, and his contamination fears had also diminished. The intervention also appeared to be helpful in alleviating James's symptoms of mental contamination. However, these therapy gains were not stable, and an increase in mental contamination (although not near the initial level) was seen at the follow-up assessment. It is unknown why his mental contamination fears showed a partial return, particularly in light of the stability of other treatment gains.

Session by session measures showed that the majority change in morphing fear symptoms occurred in the first six sessions of therapy. Accordingly, in the fifth treatment session James expressed that he noticed a decline in his compulsive routines. By the ninth session he reported 
feeling less diminished and less susceptible to morphing, and this change was reflected on the MFQ in the research assessment held the following week. Overall, the data indicate the largest treatment gains were made by the tenth session. This has implications for clinical practise in that a brief 10session intervention may be sufficient for less complex symptoms, such as morphing fears without co-morbid depression. In the case of James, complicating factors in treatment included severe depression, maladaptive perfectionism, disorganisation, and poor homework compliance.

A key strength of this research rests in the fact that this study is the first to systematically use a valid and reliable measure in the assessment of morphing fears over the course of the intervention. Previously reported intervention studies did not use a specific measure of morphing fears and operationalized treatment gains through general OCD reduction. This did not allow for confident conclusion about treatment efficacy for these fears specifically. Any future intervention studies would benefit from using the MFQ to quantify and compare morphing fear symptom change.

Another strength lay in the use of continuous assessments to help rule out threats to internal validity (Engel \& Schutt, 2009; Kazdin, 1982). Retaining internal validity was also aided by using an independent assessor who was blind to when the treatment began. This may have helped reduce observer expectancy effect and placed fewer demands on the patient to report treatment gains.

Treatment effects were detected in various ways, accumulating evidence for the causal role of the intervention. For one, visual inspection of the data - a stringent and reliable method in identifying treatment effects_ — consistently indicated a systematic intervention effect; on numerous measures symptoms were at the opposite extremes of the assessment range before and after therapy signifying unparalleled stability in the data (cf. Kazdin, 1982). A high rate of symptom decline on most measures, alongside decreased variability on the VAS assessment towards the end of treatment was also indicative of the effectiveness of treatment (cf. Kazdin, 1982). 
A limitation of this study is that baseline measures were only collected at two points in time (as opposed to the minimum recommendation of three for an experimental design, cf. Kratochwill et al., 2010; Morgan \& Morgan, 2009) making this design quasi-experimental. A second limitation is that symptom reduction seen over the treatment phase did not provide unequivocal evidence for treatment efficacy using this single-subject design; fluctuations of symptoms over time, spontaneous recovery, and/or maturation may add to or account for symptom decline (cf. Kazdin, 1982). However, due to the longstanding history of the fear in the particular case described here it is thought to be unlikely that the strongly held beliefs would have showed such marked improvement without intervention, and a more parsimonious explanation is that the intervention accounted for the changes. What can be concluded with less confidence is whether treatment gains resulted from morphing-fear-specific elements or non-specific aspects of treatment (such as CBT generally or the focus on depressive symptoms).

Future Direction: Single-subject research relies on replication and it has been recommended that 3-6 successful systematic replications should be carried out to allow for reliable causal inferences to be made (Barlow \& Hersen, 1973; Gallo, Comer \& Barlow, 2013). Use of more complex designs such as a multiple baseline design to target anxiety, depression and morphing fears in different phases of the intervention programme would strengthen the validity of subsequent research. A longer follow-up period would help determine the stability of treatment gains over time. Future research may benefit from using self-esteem and self-stability measures to examine the association between the constructs and determine the relevance of therapeutic work on self-esteem and self-stability in alleviating morphing fear.

\section{Conclusion}

This study has shown treatment success following a theoretically grounded cognitively-focused CBT intervention for morphing fears in an OCD patient who had not been helped by previous treatments. Independent assessments and self-report session-by-session measures indicated that this 
specifically-tailored CBT was effective in reducing morphing fears and other symptoms including anxiety and depression. The unique symptoms presented in the described case illustrate the need to appropriately conceptualize and address the specific nature of morphing fear symptoms in treatment. The positive treatment gains exhibited by the patient are encouraging and can help pave the way for a refinement of specific CBT interventions for particular concerns. If future replications support the results of this study, the described CBT variant can be considered an effective treatment for morphing fears.

Acknowledgements: This research was supported by [INFO REMOVED]. 


\section{References}

[AUTHORS REMOVED] (submitted). CBT for a fear of morphing: a case illustration. In S. Dimidjian, (Ed.), Evidence-Based Practice in Action. New York: Guilford Press.

Abramowitz, J. S.; Franklin, M.E., \& Foa, E.B. (2002). Empirical status of cognitive-behavioral therapy for obsessive-compulsive disorder: A meta-analytic review. Romanian Journal of Cognitive \& Behavioral Psychotherapies, 2(2), 89-104.

Agras, W. S., \& Berkowitz, R. (1980). Clinical research in behaviour-therapy: Halfway there. Behavior Therapy, 11, 472-487.

Agras, W. S., Walsh, B. T., Fairburn, C. G., Wilson, G. T., \& Kraemer, H.C. (2000). A multicenter comparison of cognitive-behavioural therapy and interpersonal psychotherapy for bulimia nervosa. Archives of General Psychiatry, 57, 459-466.

American Psychiatric Association. (1994). Diagnostic and Statistical Manual of Mental Disorders, 4th Edition. Washington, D.C: American Psychiatric Association.

Barlow, D. H. (1981). On the relation of clinical research to clinical practice: Current issues, new directions. Journal of Consulting and Clinical Psychology, 49, 147-155.

Barlow, D. H. \& Hersen, M. (1973). Single-case experimental designs: Uses in applied clinical research. Archives of General Psychiatry, 29(3), 319-325.

Bhar, S. S., \& Kyrios, M. (2007). An investigation of self-ambivalence in obsessive-compulsive disorder. Behaviour research and therapy, 45(8), 1845-1857.

Beck, J. S. (1995). Cognitive therapy: Basics and beyond. New York: Guilford.

Beck, A. T., Epstein, N., Brown, G., \& Steer, R. A. (1988). An inventory for measuring clinical anxiety: psychometric properties. Journal of Consulting and Clinical Psychology, 56, 893-897.

Beck, A. T., \& Steer, R. A. (1990). Beck Anxiety Inventory manual. San Antonio, TX: The Psychological Corporation. 
Beck, A. T., Steer, R. A., \& Brown, G. K. (1996). Manual for the Beck Depression Inventory-II. San Antonio, TX: Psychological Corporation.

Blampied, N. M. (1999). A legacy neglected: Restating the case for single-case research in cognitive-behaviour therapy. Behaviour Change, 16, 89-104.

Boschen, M. J., Drummond, L.M., \& Pillay, A. (2008). Treatment of severe, treatment refractory obsessive-compulsive disorder: a study of inpatient and community treatment. CNS Spectrums, $13,1056-1065$.

Brown, T. A., Di Nardo, P., \& Barlow, D. H. (1994). Anxiety disorders interview schedule adult version (ADIS-IV): Client interview schedule. Oxford: Oxford University Press.

Calamari, J. E., Weigartz, P. S., Riemann, B. C., Cohen, R. J., Greer, A., Jacobi, D.M.,... Carmin, C. (2004). Obsessive-compulsive disorder subtypes: an attempted replication and extension of a symptom-based taxonomy. Behaviour Research and Therapy, 42, 647-70.

Campbell, J.D. (1990). Self-esteem and clarity of the self-concept. Journal of Personality \& Social Psychology, 59(3), 538-549.

Campbell, J.D. \& Lavallee, L.F. (1993). Who am I? The role of self-concept confusion in understanding the behaviour of people with low self-esteem. In R.F. Baumeister (Ed.), Selfesteem: The puzzle of low self-regard (3-20). Plenum Press, New York, NY.

Coughtrey A. E., Shafran, S., Lee, M., \& Rachman, S. J. (2013). The Treatment of Mental Contamination: A Case Series. Cognitive and Behavioural Practice, 20(2), 221-231.

Coughtrey, A. E., Shafran, R., Knibbs, D., \& Rachman, S. J. (2012a). Mental contamination in obsessive-compulsive disorder. Journal of Obsessive Compulsive and Related Disorders, 1 , $244-250$.

Creamer, M., Foran, J., \& Bell R. (1995). The Beck Anxiety Inventory in a non-clinical sample. Behaviour Research and Therapy, 33, 477-485. 
Donahue, E.M., Robins, R.W., Roberts, R.W., \& John, O.P. (1993). The divided self: Concurrent and longitudinal effects of psychological adjustment and social roles on self-concept differentiation. Journal of Personality \& Social Psychology, 64 (5), 834-846.

Eddy, K. T., Dutra, L., Bradley, R., \& Westen, D. (2004). A multidimensional meta-analysis of psychotherapy and pharmacotherapy for obsessive-compulsive disorder. Clinical Psychology Review, 24(8), 1011-1030.

Egan, S. J., \& Hine, P. (2008). Cognitive behavioural treatment of perfectionism: A single case experimental design series. Behavioural Change, 25(4), 245-258.

Engel, R. \& Schutt, R. (2009). The Practice of Research in Social Work. $2^{\text {nd }}$ Ed. London: Sage. Fairbrother, N., \& Rachman, S. (2004). Feelings of mental pollution subsequent to sexual assault. Behaviour Research and Therapy, 42, 173-189.

Fairburn C. G. (1995). Overcoming binge eating. New York: Guilford Press.

Ferguson, C. J. (2009). An effect size primer: A guide for clinicians and researchers. Professional Psychology: Research and Practice, 40, 532-538.

Ferrier, S., \& Brewin, C. R. (2005). Feared identity and obsessive-compulsive disorder. Behaviour Research and Therapy, 43, 1363 - 1374.

Fisher, P., \& Wells, A. (2005). How effective are cognitive and behavioural treatments for OCD? A clinical significance analysis. Behaviour Research and Therapy, 43, 1543-1558.

Foa, E. B., Huppert, J. D., Leiberg, S., Langner, R., Kichic, R., Hajcak, G., \& Salkovskis, P. M. (2002). The Obsessive-Compulsive Inventory: Development and validation of a short version. Psychological Assessment, 14(4), 485-496.

Foa, E. B., \& Kozak, M. J. (1995). DSM-IV Field Trial: Obsessive-Compulsive Disorder. American Journal of Psychiatry, 152, 90-96. 
Freeston, M. H., Ladouceur, R., Gagnon, F., Thibodeau, N., Rhéaume, J., Letarte, H., \& Bujold, A. (1997). Cognitive behavioural treatment of obsessive thoughts: a controlled study. Journal of Consulting and Clinical Psychology, 65(3), 405-413.

Frost, R. O., Steketee, G., Krause, M. S., \& Trepanier, K. L. (1995). The relationship of the YaleBrown Obsessive Compulsive Scale (YBOCS) to other measures of obsessive compulsive symptoms in a non-clinical population. Journal of Personality Assessment, 65(1), 158-168.

Fydrich, T., Dowdall, D., \& Chambless, D. L. (1992). Reliability and validity of the Beck Anxiety Inventory. Journal of Anxiety Disorders, 6(1), 55-61.

Gallo, K. P., Comer, J. S., \& Barlow, D. H. (2013). Direct-to-consumer marketing of psychological treatments for anxiety disorders. Journal of Anxiety Disorders, 27, 793-801.

Gillis, M. M., Haaga, D. A. F., \& Ford, G. T. (1995). Normative values for the Beck Anxiety Inventory, Fear Questionnaire, Penn State Worry Questionnaire, and Social Phobia Anxiety Inventory. Psychological Assessment, 7, 450-455.

Goodman, W. K., Price, L. H., Rasmussen, S. A., Mazure, C., Fleischmann, R. L., Hill, C. L., ... Charney, D. S. (1989a). The Yale-Brown obsessive compulsive scale: I. Development, use, and reliability. Archives of General Psychiatry, 46, 1006-1011.

Goodman, W. K., Price, L. H., Rasmussen, S. A., Mazure, C., Delgado, P., Heninger, G. R., \& Charney, D. S. (1989b). The Yale-Brown obsessive compulsive scale: II. Validity. Archives of General Psychiatry, 46, 1012-1016.

Guidano, V., \& Liotti, G. (1983). Cognitive processes and emotional disorders. New York: Guildford Press.

Hawkins, R. P., \& Dobes, R. W. (1977). Behavioral definitions in applied behaviour analysis: Explicit or implicit? In B. C. Etzel, J. M. LeBlanc, \& D. M. Baer (Eds.), New developments in behavioral research: Theory, method, and application (167-188). Hillsdale, NJ: Erlbaum. 
Hevia, C. (2009). Emotional contamination: A lesser known subtype of OCD. OCD Newsletter, 23(4), 10-12.

Horner, R. H., Carr, E. G., Halle, J., McGee, G., Odom, S., Wolery, M. (2005). The use of single subject research to identify evidence-based practice in special education. Exceptional Children, $71(2), 165-179$.

Jacobson, N. S., \& Truax, P. (1991). Clinical significance: A statistical approach to defining meaningful change in psychotherapy research. Journal of Consulting and Clinical Psychology, 59, 12-19.

Kazdin, A. E. (1982). Single case research designs: methods for clinical and applied settings. New York, Oxford University Press.

Keeley, M. L., Storch, E. A., Merlo, L. J., \& Geffken, G. R. (2008). Clinical predictors of response to cognitive-behavioral therapy for obsessive-compulsive disorder. Clinical psychology review, 28(1), 118-130.

Kratochwill, T. R., Hitchcock, J., Horner, R. H., Levin, J. R., Odom, S. L., Rindskopf, D. M., \& Shadish, W. R. (2010). Single-case design technical documentation. Retrieved $6^{\text {th }}$ July 2016. Available from What Works Clearinghouse: http://ies.ed.gov/ncee/wwc/pdf/wwc_scd.pdf

Lambert, M. J. (2009). Yes, it is time for clinicians to routinely monitor treatment outcome. In B. L. Duncan, S. D. Miller, B. E. Wampold, \& M. A. Hubble (Eds.), The heart and soul of change: Delivering what works in therapy (2 ${ }^{\text {nd }}$ ed., 239-266). Washington, DC: American Psychological Association.

Lambert, M. J., Whipple, J. L., Smart, D. W., Vermeersch, D. A., Nielsen, S. L., \& Hawkins, E. J. (2001). The effects of providing therapists with feedback on patient progress during psychotherapy: Are outcomes enhanced? Psychotherapy Research, 11, 49-68.

Lipton, M.G., Brewin, C.R., Linke, S., \& Halperin, J. (2010). Distinguishing features of intrusive images in obsessive-compulsive disorder. Journal of Anxiety Disorders, 24, 816-822 
Manolov R, Losada J.L., Chacón-Moscoso, S. \& Sanduvete-Chaves, S. (2016) Analyzing twophase single-case data with non-overlap and mean difference indices: Illustration, software tools, and alternatives. Frontiers in Psychology,. 7(32), 1-16.

McCormack, H. M., Horne, D. J. D., \& Sheather, S. (1988). Clinical applications of visual analogue scales: A critical review. Psychological Medicine, 18, 1007-1019.

McLean, P.D., Whittal, M. L., Thordarson, D. S., Taylor, S., Söchting, I., Koch, W. J., ... \& Anderson, K. W. (2001). Cognitive versus behavior therapy in the group treatment of obsessive-compulsive disorder. Journal of Consulting and Clinical Psychology, 69(2), 205214.

Monzani, B., Jassi, A., Heyman, I., Turner, C., Volz, C., \& Krebs, G. (2015). Transformation obsessions in paediatric obsessive-compulsive disorder: Clinical characteristics and treatment response to cognitive behaviour therapy. Journal of Behavior Therapy and Experimental Psychiatry, 48, 75-81.

Morgan, D. L. \& Morgan, R. K. (2009). Single-Case Research Methods for the Behavioral and Health Sciences. Los Angeles: Sage.

National Institute for Clinical Excellence (2005). Obsessive-compulsive disorder: core interventions in the treatment of obsessive-compulsive disorder and body dysmorphic disorder (NICE Clinical Guideline No. 31). London: HMSO.

Nikodijevic, A., Moulding, R., Anglim, J., Aardema, F., \& Nedeljkovic, M. (2015). Fear of self, doubt and obsessive compulsive symptoms. Journal of behavior therapy and experimental psychiatry, 49(Pt B):164-72.

O'Connor, K.P., Aardema, F., Bouthillier, D., Fournier, S. Guay, S. Robillard, S. et al. (2005). Evaluation of an inference-based approach to treating obsessive-compulsive disorder. Cognitive Behaviour Therapy, 34(3), 148-163. 
Parker, R. I., \& Vannest, K. J. (2009). An improved effect size for single case research: Nonoverlap of all pairs (NAP). Behavior Therapy, 40(4), 357-367.

Parker, R. I., Vannest, K. J., Davis, J. L. \& Sauber, S. B. (2011). Combining non-overlap and trend for single case research: Tau-U, Behavior Therapy, 42, 284-299.

Parsonson, B., \& Baer, D. M. (1986). The graphic analysis of data. In Poling, A. \& Fuqua, R. W. (Eds.), Research methods in applied behavior analysis (pp. 157-186). New York: Plenum.

Rachman, S. J. (1994). Pollution of the mind. Behaviour Research and Therapy, 32, 311-314.

Rachman, S. J. (2003). The treatment of obsessions. Oxford: Oxford University Press.

Rachman, S. J. (2004). Fear of contamination. Behaviour Research and Therapy, 42, 1227-1255.

Rachman, S. J. (2006). The fear of contamination: Assessment and treatment. Oxford: Oxford University Press.

Rachman, S. J., Coughtrey, A. E., Shafran, R. \& Radomsky, A. S. (2015). The Oxford Guide to the Treatment of Mental Contamination. New York, NY: Oxford University Press.

Rachman, S. J., \& Hodgson, R. J. (1980). Obsessions and compulsions. Englewood Cliffs, NJ: Prentice Hall.

Rachman S. J., Radomsky, A. S., Elliott, C. M., \& Zysk, E. (2012). Mental contamination: The perpetrator effect. Journal of Behaviour Therapy and Experimental Psychiatry, 43(1), 587-593.

Radomsky, A., \& Elliott, C. M. (2009). Analyses of mental contamination: Part II, individual differences. Behaviour Research and Therapy, 47, 1004-1011.

Radomsky, A. S., Rachman, S. J., Shafran, R., Coughtrey, A. E., \& Barber, K. C. (2014). The nature and assessment of mental contamination: A psychometric analysis. Journal of Obsessive-Compulsive and Related Disorders, 3, 181-187.

Rasmussen, S. A., \& Eisen, J. L. (1992). The epidemiology and differential diagnosis of obsessive compulsive disorder. Journal of Clinical Psychiatry, 53, 4-10. 
Reips, U. D., \& Funke, F. (2008). Interval-level measurement with visual analogue scales in Internet-based research: VAS Generator. Behavior Research Methods, 40(3), 699-704.

Riley, C., Lee, M., Cooper, Z., Fairburn, C. G., \& Shafran, R. (2007). A randomised controlled trial of cognitive behaviour therapy for clinical perfectionism: A preliminary study. Behaviour Research and Therapy, 45, 2221-2231.

Salkovskis, P. M. (2002). Empirically grounded clinical interventions: Cognitive-behavioural therapy progresses through a multi-dimensional approach to clinical science. Behavioural and Cognitive Psychotherapy, 30, 3-9.

Scahill, L., Riddle, M. A., McSwiggin-Hardin, M., Ort, S. I., King, R. A., Goodman, W. K., ... Leckman, J. F. (1997). Children's Yale-Brown obsessive compulsive scale: reliability and validity. Journal of the American Academy of Child \& Adolescent Psychiatry, 36, 844-852.

Shadish, W.R., Cook, T.D. \& Campbell, D.T. (2002). Experimental and quasi-experimental designs for generalized causal inference. Boston: Houghton Mifflin.

Shafran, R., Egan, S., \& Wade, T. (2010). Overcoming perfectionism. London: Robinson.

Shafran, R., Thordarson, D. S., \& Rachman, S. J. (1996). Thought-action fusion in obsessivecompulsive disorder. Journal of Anxiety Disorders, 10, 379-391.

Sookman, D., Abramowitz, J. S., Calamari, J. E., Wilhelm, S., \& McKay, D. (2005). Subtypes of obsessive compulsive disorder: Implications for specialised cognitive behaviour therapy. Behaviour Therapy, 36(4), 393-400.

Taylor, S. (1995). Assessment of obsessions and compulsions: reliability, validity, and sensitivity to treatment effects. Clinical Psychology Review, 15(4), 261-296.

Thordarson, D.S., Radomsky, A. S., Rachman, S., Shafran, R., Sawchuck, C. N., \& Hakstian, A. (2004). The Vancouver Obsessional Compulsive Inventory (VOCI). Behaviour Research and Therapy, 42, 1289-1314. 
Tolin, D. F., Abramowitz, J. S., \& Diefenbach, G. J. (2005). Defining response in clinical trials for Obsessive-Compulsive Disorder: A signal detection analysis of the Yale-Brown Obsessive Compulsive Scale. Journal of Clinical Psychiatry, 66(12), 1549-1557.

Valsiner, J. (1986). The individual subject and scientific psychology. New York: Plenum.

Vannest, K.J., Parker, R.I., \& Gonen, O. (2011). Single Case Research: web based calculators for SCR analysis. (Version 1.0) [Web-based application]. College Station, TX: Texas A\&M University. Retrieved 16th July 2015. Available from singlecaseresearch.org Volz, C., \& Heyman, I. (2007). Case series: Transformation obsession in young people with obsessive-compulsive disorder (OCD). Journal of the American Academy of Child \& Adolescent Psychiatry, 46(6), 766-772.

Whisman, M. A., Perez, J. E., \& Ramen, W. (2000). Factor structure of the Beck Depression Inventory-II in a student sample. Journal of Clinical Psychology, 56, 545-551.

Whittal, M. L, Robichaud, M., \& Woody, S. R. (2010). Cognitive treatment of obsessions: Enhancing dissemination with video components. Cognitive and Behavioral Practice, 17(1), 18.

Whittal, M. L., Woody, S. R., McLean, P. D., Rachman, S. J., \& Robichaud, M. (2010). Treatment of obsessions: A randomised controlled trial. Behaviour Research and Therapy, 43, 15591576.

Wilhelm, S., Steketee, G., Fama, J. M., Buhlmann, U., Teachman, B. A., Golan, E. (2009). Modular cognitive therapy for obsessive-compulsive disorder: A wait-list controlled trial. Journal of Cognitive Psychotherapy, 23(4), 294-305.

Williams, T. I., Salkovskis, P. M., Forrester, E. A., \& Allsopp, M. A. (2002). Changes in symptoms of OCD and appraisal of responsibility during cognitive behavioural treatment: A pilot study. Behavioural and Cognitive Psychotherapy, 30, 69-78. 
Wu, K.D., Aardema, F., \& O'Connor, K.P. (2009). Inferential confusion, obsessive beliefs, and obsessive-compulsive symptoms: a replication and extension. Journal of Anxiety Disorders, 23, $746-752$

Zysk, E., Shafran, R., Williams, T. \& Melli, G. (2015). Development and validation of the Morphing Fear Questionnaire (MFQ). Clinical Psychology \& Psychotherapy. 
Table 1 Outcomes of the research assessments collected at each of the 5 time points

\begin{tabular}{|c|c|c|c|c|c|c|c|c|}
\hline $\begin{array}{c}\text { Week } \\
\text { \# }\end{array}$ & $\begin{array}{c}\text { Intervention } \\
\text { Stage }\end{array}$ & $\begin{array}{l}\text { ADIS-IV } \\
\text { Diagnoses }\end{array}$ & $\begin{array}{c}Y- \\
B O C S\end{array}$ & $M F Q$ & $\begin{array}{l}\text { VOCI- } \\
\text { MC }\end{array}$ & $\begin{array}{l}O C I \\
-R\end{array}$ & $B A I$ & $\begin{array}{c}B D I- \\
\quad I I\end{array}$ \\
\hline 0 & Baseline 1 & $\begin{array}{l}\text { OCD, depression, } \\
\text { mild social phobia, } \\
\text { mild GAD }\end{array}$ & 31 & 29 & 59 & 52 & 24 & 42 \\
\hline 9 & Baseline 2 & $\begin{array}{l}\text { OCD, depression, } \\
\text { mild social phobia, } \\
\text { GAD }\end{array}$ & 27 & 28 & 56 & 37 & 12 & 43 \\
\hline 20 & $\begin{array}{c}\text { Post session } \\
10\end{array}$ & $\begin{array}{l}\text { OCD, depression, } \\
\text { mild social phobia, } \\
\text { GAD }\end{array}$ & 27 & 10 & N/A & N/A & N/A & N/A \\
\hline 28 & $\begin{array}{l}\text { Post session } \\
13\end{array}$ & $\begin{array}{l}\text { Mild OCD, mild } \\
\text { social phobia, mild } \\
\text { GAD }\end{array}$ & 20 & 3 & 13 & 12 & 4 & 18 \\
\hline 36 & Follow-Up & $\begin{array}{l}\text { Mild OCD, mild } \\
\text { GAD }\end{array}$ & 14 & 1 & 37 & 15 & 4 & 2 \\
\hline
\end{tabular}


Table 2 Clinical significance of changes in measures over baseline (mean scores of Weeks 0 and 9) and posttreatment (Week 36) phases

\begin{tabular}{lccccc} 
Assessment & Baseline & Post-Treatment & Non-clinical & Clinical & Clinical Significance \\
Measure & Mean & Score & Mean & Mean & Achieved \\
\hline MFQ & 28.5 & 1 & 1.8 & 7.6 & Yes \\
VOCI-MC & 57.5 & 37 & 8.3 & 30.6 & No \\
OCI-R & 44.5 & 15 & 18.8 & 28.0 & Yes \\
BAI & 18.0 & 4 & $6.6-13.4$ & 24.6 & Yes \\
BDI-II & 42.5 & 2 & $8.4-12.6$ & 21.9 & Yes \\
Y-BOCS & 29.0 & 14 & $<13$ & $>16$ & Yes
\end{tabular}


Figure 1 Clinical formulation for James's morphing fears depicting triggers, symptoms, appraisals, and specific mechanisms thought to be maintaining the patient's disorder

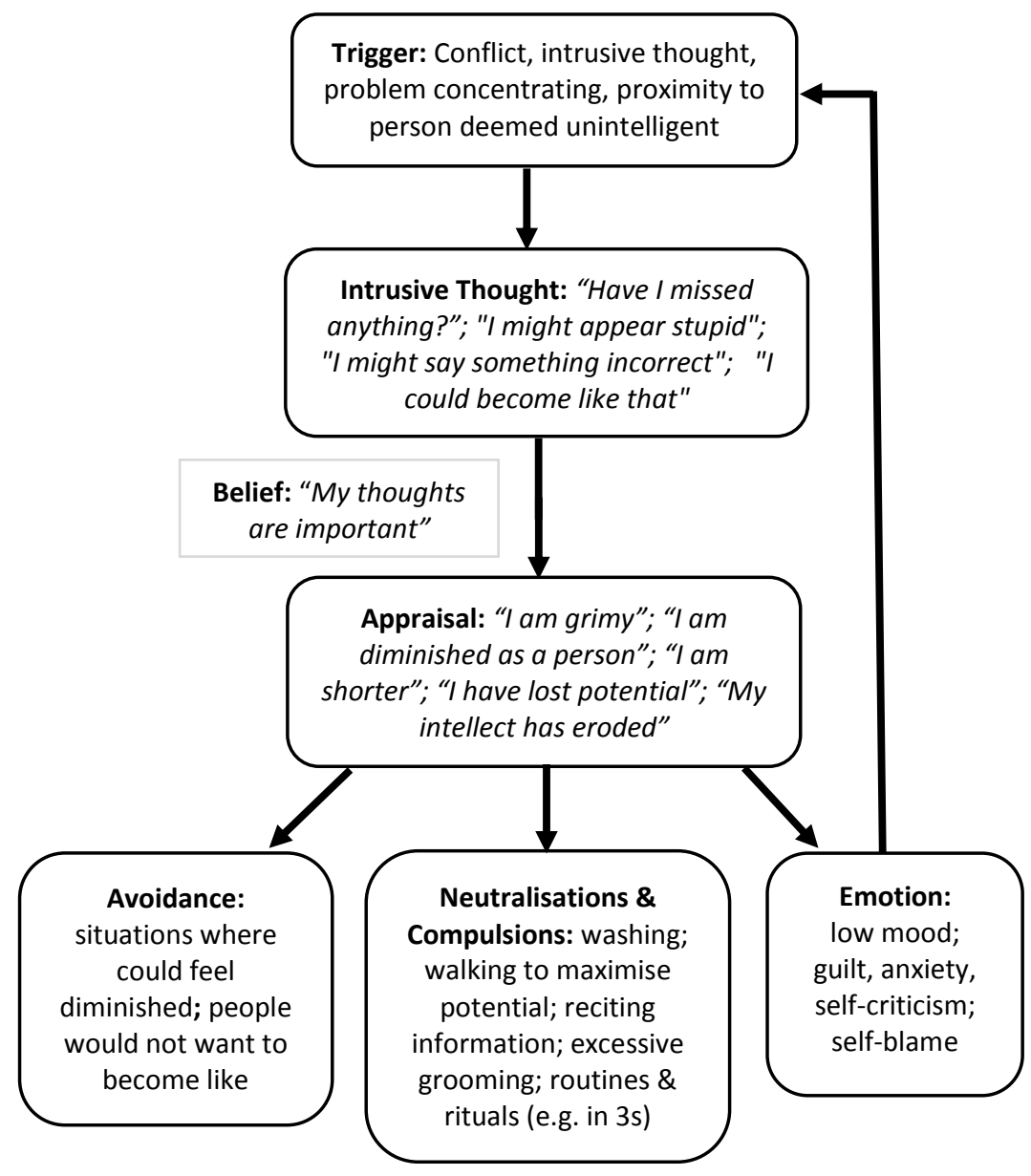


Figure 2 Symptoms of morphing fears at each research assessment

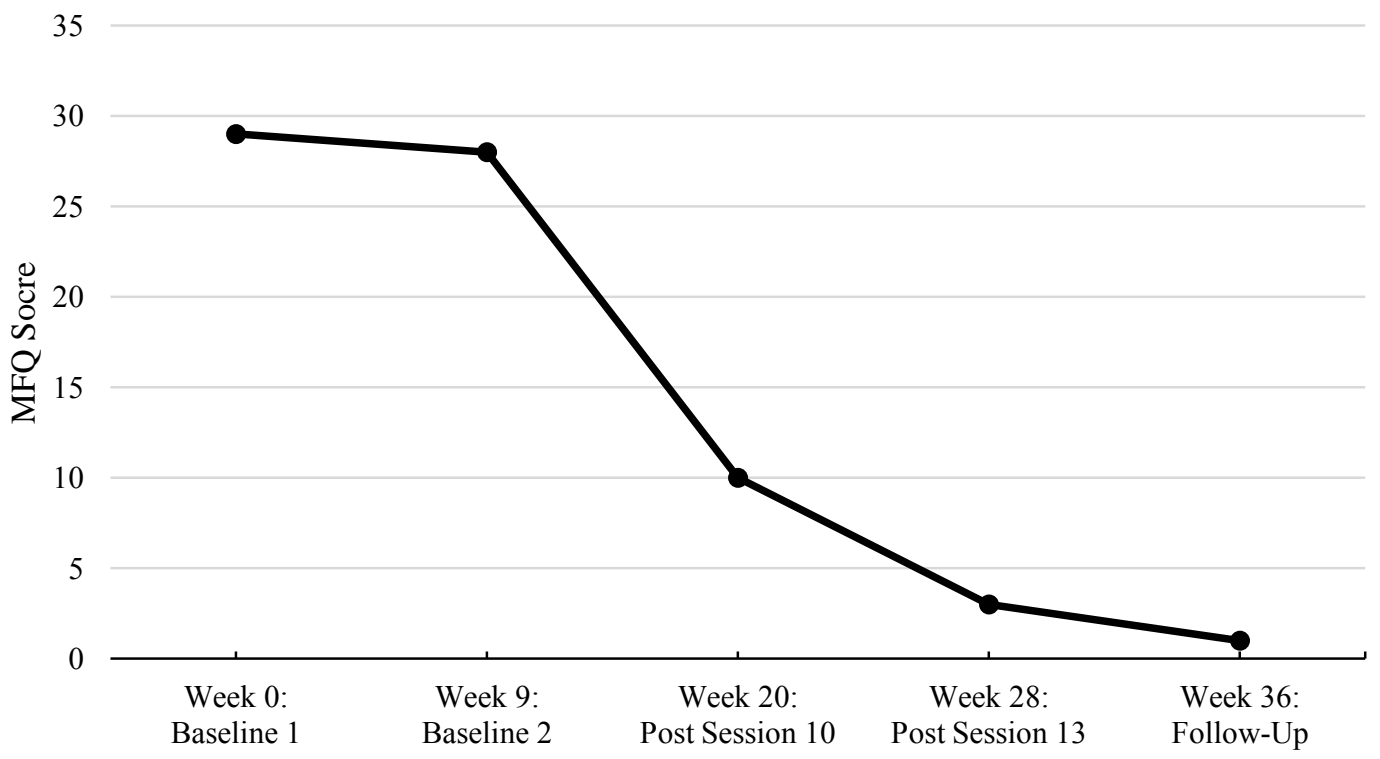


Figure 3 Symptoms of OCD (Y-BOCS) at each research assessment

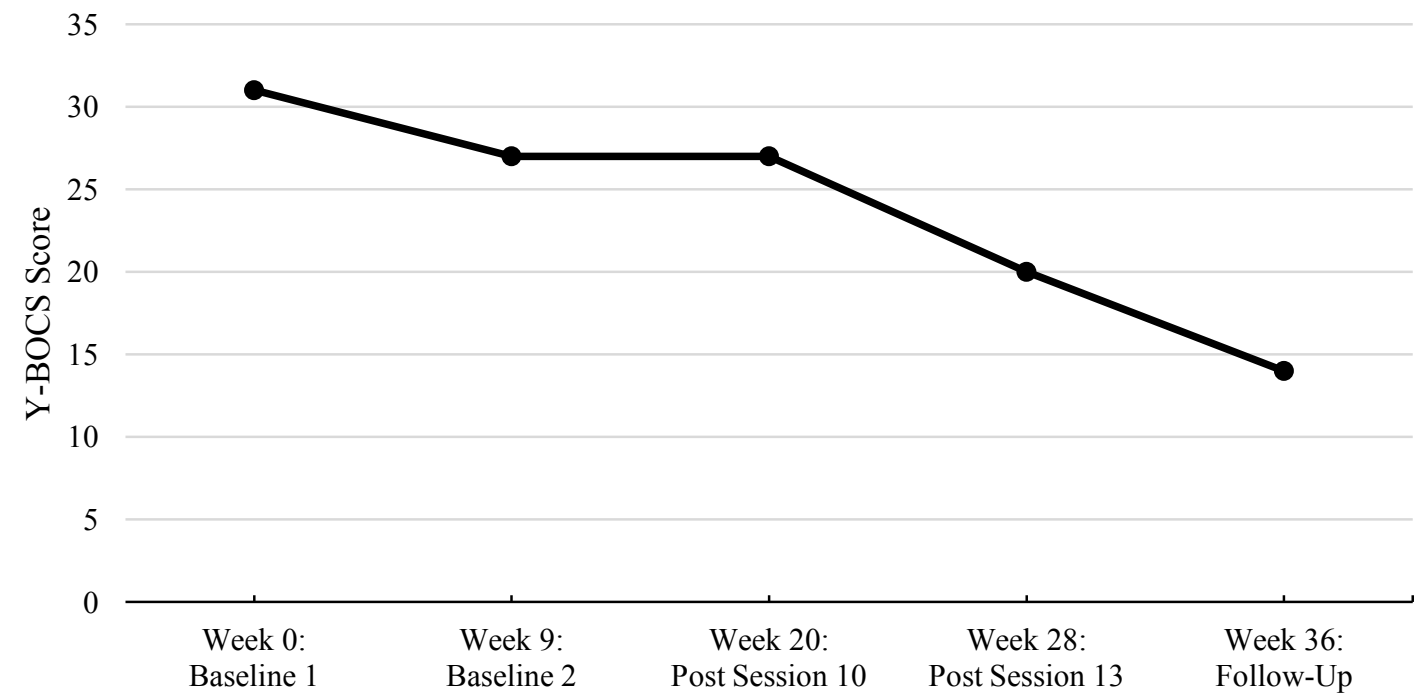


Figure 4 Symptoms of OCD (OCI-R), anxiety and depression at each research assessment

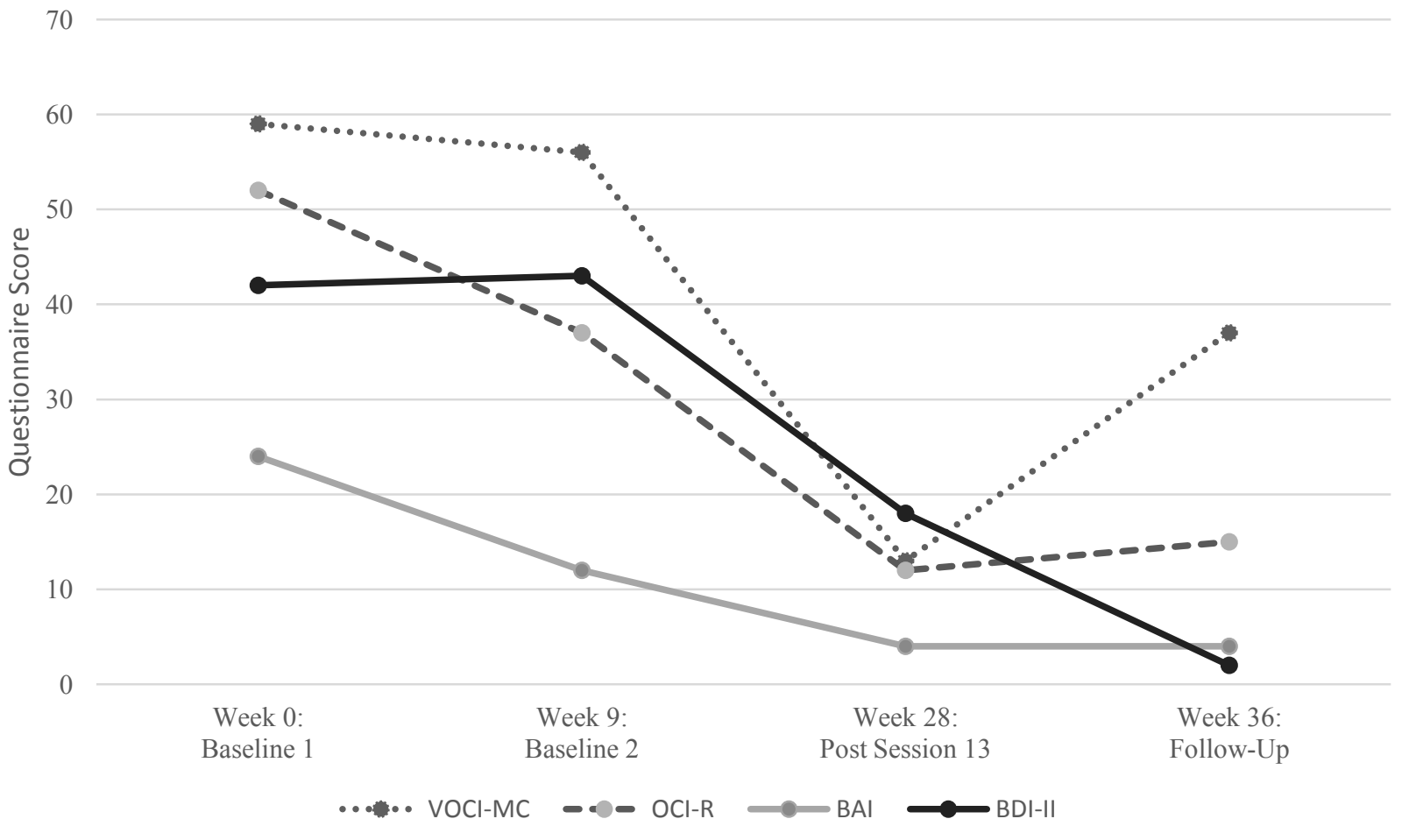


Figure 5 Symptoms reported on the VAS at baseline, in each treatment session, and at follow-up

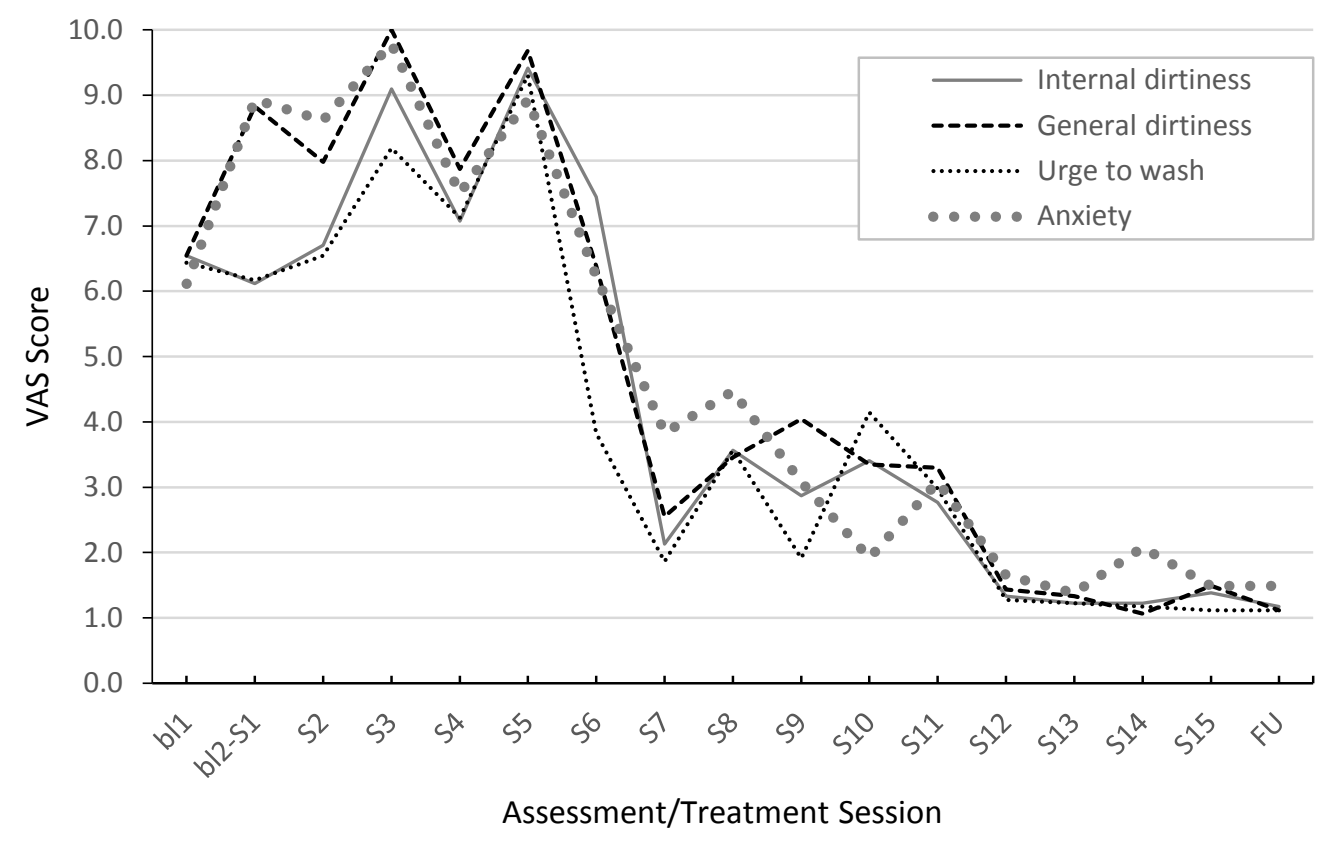

